\title{
Three cases of nalbuphine hydrochloride dependence associated with anabolic steroid use
}

\author{
Andrew J McBride, Kath Williamson, Trudi Petersen
}

\begin{abstract}
Three case reports are presented of nalbuphine hydrochloride dependence meeting DSM IIIR and ICD10 criteria for opioid dependence. Nalbuphine hydrochloride is being obtained from illicit sources and used by those using performance enhancing drugs. In some cases this leads to opioid dependence. There is a potential risks of crossover between the misuse of drugs of performance and the misuse of psychoactive drugs by injection. Further research into the dependence potential of nalbuphine and the extent of the crossover between steroid misuse and other psychoactive drug misuse is required. The legal status of nalbuphine should be reviewed in the light of its availability on the black market.

(Br $\mathcal{F}$ Sports Med 1996;30:69-70)
\end{abstract}

Key terms: nalbuphine hydrochloride; anabolic steroids; opioid dependence.

We report three anabolic steroid users presenting to a well steroid user clinic, ${ }^{1}$ complaining of nalbuphine hydrochloride dependence. Nalbuphine (Nubain) is an opioid agonist/ antagonist analgesic licensed for the treatment of moderate to severe pain. The recommended daily dosage is $10-20 \mathrm{mg}$ for a $70 \mathrm{~kg}$ man. DuPont Pharmaceuticals manufacture the drug in injectable form only, for subcutaneous, intramuscular, or intravenous use. Nalbuphine is not controlled under the Misuse of Drugs Act (1971) in the United Kingdom, nor classified as a narcotic in any country. ${ }^{2}$

\section{Case reports}

CASE 1

Mr A, a 27 year old divorced anabolic steroid dealer and unemployed roofer, presented complaining of withdrawal symptoms within hours of discontinuing nalbuphine. He had used black market nalbuphine over a nine month period, initially $10 \mathrm{mg}$ three times daily subcutaneously, to relieve pain from a rugby injury. He initially experienced no symptoms of dependence, but felt relaxed and "spaced out" by the drug. Gradually, he recognised tolerance to the drug's effects, and irritability and abdominal discomfort between doses. He changed to intravenous use and gradually increased the dose to $160-200 \mathrm{mg}$ daily.
Two attempts to stop nalbuphine had resulted in nausea, abdominal cramps, diarrhoea, shaking, and sweating. Increasing intensity on the second day of abstinence led to further use of nalbuphine and resolution of symptoms.

Mr A had used anabolic steroids intermittently for five years. During his 9 month period of nalbuphine use, he used clenbuterol, three tablets daily, testosterone propionate, $250 \mathrm{mg}$ on alternate days, and human chorionic gonadotrophin, every 11 days. $\mathrm{He}$ had not changed this regimen when stopping the nalbuphine.

$\mathrm{He}$ had smoked cannabis regularly for several years, and misused temazepam over a six week period, including by intravenous injection, 5 years previously.

CASE 2

$\mathrm{Mr} \mathrm{B}$, a 22 year old single unemployed gym manager, presented complaining of withdrawal symptoms on stopping nalbuphine and an overwhelming preoccupation with the drug.

A competitive bodybuilder, $\mathrm{Mr} \mathrm{B}$ had used black market nalbuphine for two years, initially to allow him to train "through the pain barrier" (to train despite musculoskeletal pain), and to keep calm preparing for competition. Nalbuphine use had always been intravenous: an "unbelievable" (pleasurable) experience. His maximum daily dose had been $100 \mathrm{mg}$, but at presentation he had deliberately reduced this to $40 \mathrm{mg}$ in three divided doses.

$\mathrm{Mr} \mathrm{B}$ recognised a problem with nalbuphine when he experienced mood swings and irritability as the effects wore off. $\mathrm{He}$ had attempted to stop the drug on one occasion and experienced sweating, tremor, abdominal cramps, and "flu-like" symptoms. He therefore restarted it after three days, with immediate alleviation of his symptoms. A teetotaller, $\mathrm{Mr}$ $B$ had initially used nalbuphine in conjunction with anabolic steroids, clenbuterol, ephedrine, and tamoxifen, all to aid bodybuilding. He had used only nalbuphine for 12 months. There was no other history of psychoactive drug misuse.

CASE 3

$\mathrm{Mr} \mathrm{C}$, a 26 year old gym owner, had used black market nalbuphine intramuscularly for two years, initially for pain from a back injury. $\mathrm{He}$ had used the drug intravenously for only 11 days when he attended clinic, during which 
time he had increased the dose rapidly to $100-120 \mathrm{mg}$ in eight injections daily. He felt unable to control his use and described strong cravings both for nalbupine and injecting. He developed stomach cramps four hours after each injection and had never allowed any further symptoms to develop.

When first seen $\mathrm{Mr} \mathrm{C}$ was also using illicit amphetamine sulphate powder, approximately $0.5 \mathrm{~g}$ daily orally and $1.75 \mathrm{~g}$ of cannabis daily. $\mathrm{He}$ had used anabolic steroids in the past, but not for two years.

Each of the three cases fulfilled DSM3-R (304.0) and ICD 10 (F11.24) criteria for opioid dependence.

\section{Discussion}

Neither a MEDLINE search nor the manufacturers identified any reports of nalbuphine dependence using recognised diagnostic criteria. These cases are also the first reports of opioid dependence resulting from drug use connected with competitive sports. McGarity reported treating six patients within one year "abusing either Nubain or Stadol." Two were considerd by the author to be both psychologically and physiologically dependent. ${ }^{3}$ There has been one further case report of a 44 year old male physician, "addicted" to nalbuphine and diphenhydramine, with a six month history of intramuscular and subcutaneous injection. ${ }^{4}$ No further details of the cases were given. Up to 1985 there had been four notifications to the manufacturers of alleged nalbuphine "dependence," but no reports of "street use". 2

A press report has claimed that nalbuphine use by steroid users is the "latest drugs craze to sweep... gyms" in the south west of England (Western Daily Press, 21 June 1994), and the authors have had enquiries from drugs agencies across England and Wales which have identified further individual cases of nalbuphine misuse or dependence, always anabolic steroid users, and always accompanied by anecdotal information of much more widespread use. On the black market at 1994 prices, nalbuphine cost £25-45 for ten $20 \mathrm{mg}$ ampoules.

Users have reported several reasons for taking nalbuphine: to overcome musculoskeletal pain, despite the risk of injury, to keep calm before competition, and to take part in sport or training after injury. Less understandably, an anticatabolic effect has been claimed for nalbuphine, which has also been used to induce sleep following growth hormone use ${ }^{5}$ to enhance the effects.

All three individuals described here took doses of nalbuphine above the recommended maximum. Unpleasant subjective effects have been described with doses above $147 \mathrm{mg}$, ${ }^{6}$ but such symptoms did not occur in our cases. Before they became addicted to nalbuphine all three men had previously used drugs intramuscularly, and one had used it intravenously. The high doses and choice of the intravenous route may reflect the evolving process of opioid dependence, but may also have contributed to the development of dependence symptoms, particularly in case 3, in which doses increased very rapidly after the change to intravenous use.

No case had experienced the withdrawal symptoms associated with anabolic steroids, suggesting that their symptoms can properly be attributed to the nalbuphine.

The only published evaluation of abuse potential during chronic administration of nalbuphine was limited to six prisoners with a history of "opiate abuse," given the drug subcutaneously. Nalbuphine produced "some opiate-like effects" and 4 to $6 \mathrm{mg}$ of naloxone precipitated an opioid abstinence syndrome in all six subjects. ${ }^{6}$

In the United States two studies have shown positive correlations between anabolic steroid use and use of other illicit drugs in young people, but opioid use is not referred to specifically. ${ }^{8} 9$ The extent of anabolic steroid use by polydrug users in Britain is largely unknown, as is the extent of crossover from steroid use to other drug use. ${ }^{10}$

Two cases of HIV infection associated with intramuscular use of anabolic steroids have been reported ${ }^{1112}$ and it has been predicted that within a decade HIV infected anabolic steroid users might be presenting to services. ${ }^{13}$ Polydrug use, with the risk of cross infection, puts the anabolic steroid user at increased risk of contracting HIV and hepatitis, and the non-steroid user at potential risk of JakobCreutzfeldt disease. ${ }^{5}$

These cases suggest a need for further research into the relaton between anabolic steroid and other drug use, and the extent of high risk behaviour. It has been asked why the American Food and Drug Administration released nalbuphine without controlled status, while "in the real world" patients were becoming dependent. ${ }^{3}$ The dependence potential of nalbuphine needs to be investigated further The legal status of the drug should be reexamined in the light of this evidence that the drug has entered the black market.

1 Williamson K, Davies M, McBride A. A well steroid user clinic. Druglink 1992;7:15.

Schmidt WK, Tam SW, Shotzberger GS, Smith DH, Clark R, Vernier VG. Nalbuphine. Drug Alcohol Depend 1985;14:339-62.

3 McGarity GJ. Letter. Drug Intelligence Clin Pharm 1984; 18:78.

4 Larsen CE, Stiles RG, Davis SC. Magnetic resonance imaging of nalbuphine-induced myocutaneous sclerosis. South $M e d \% 1993 ; 86: 1296-8$.

5 Williamson $\mathrm{K}$. Creutzfeldt-Jakob disease: another avenue? Br ₹ Hosp Med 1994;51:7-8.

6 Jasinski DR, Mansky PA. Evaluation of nalbuphine for abuse potential. Clin Pharmacol Ther 1972;13:78-90.

7 Brower K, Blow FC, Young JP, Hill EM. Symptoms and correlates of anabolic-androgenic steroid dependence. correlates of anabolic-androge
$B r \mathcal{A}$ Addict $1991 ; 86: 759-68$.

8 Durant RH, Rickert VI, Ashworth CS, Newman C, Slavens $\mathrm{G}$. Use of multiple drugs among adolescents who use anabolic steroids. N Engl $\mathscr{f}$ Med 1993;328:922-6.

9 Yesalis CE, Kennedy NJ, Kopstein AN, Bahkre MS. Anabolic-androgenic steroid use in the United States. भAMA 1993;270:1217-21.

10 Korkia PK, Stimson GV. Anabolic steroid use in Great Britain an exploratory investigation. London: Centre for Research on Drugs and Health Behaviour, 1993

11 Scott MJ, Scott MJ. HIV infection associated with injections of anabolic steroids. $\mathcal{F} A M A \quad 1989 ; 262: 207-8$.

12 Sklarek HM, Mantovani RP, Erens E, Heisler D, Neiderman MS, Fein AM. AIDS in a bodybuilder usin anabolic steroids. $N$ Engl F Med 1984;311:1701.

13 Nemechek PM. Anabolic steroid users - another potential risk group for HIV infection. $N$ Engl f Med 1991;325: 357 . 